\title{
Prevalence of Eating Disorders and Disordered Eating Behaviors Among Male Collegiate Athletes
}

\author{
Trent A. Petrie and Christy Greenleaf \\ University of North Texas
}

\author{
Justine Reel \\ University of Utah
}

\author{
Jennifer Carter \\ Center for Healthy Living
}

\begin{abstract}
Male athletes have been hypothesized to be at increased risk for disordered eating attitudes and behaviors due to unique pressures in the sport environment. In this study, 203 male collegiate athletes from three universities completed the Questionnaire for Eating Disorder Diagnosis (QEDD; Mintz, O'Halloran, Mulholland, \& Schneider, 1997) as well as provided information on binge eating and pathogenic weight control behaviors. None were classified with a clinical eating disorder, though almost $20 \%$ reported a sufficient number and level of symptoms to be considered symptomatic. Just over $80 \%$ had no significant eating disorder concerns and were classified as asymptomatic. Neither year in school, race/ethnicity, sport type, nor age were related to whether or not the athletes were symptomatic or asymptomatic. In terms of the athletes' body mass, fewer than $2 \%$ were underweight and $66 \%$ were classified as overweight or obese according to CDC guidelines; over $60 \%$ were satisfied with their current body weight. Although the frequency of pathogenic behaviors was low, exercise $(37 \%)$ and fasting/dieting (14.2\%) were the primary and secondary means for controlling weight; fewer than $10 \%$ used vomiting, laxatives, or diuretics.
\end{abstract}

Keywords: eating disorders, pathogenic weight control, male athletes

Over the past 2 decades, the social value and meanings given to men's bodies have changed. In the past, men were valued because of their abilities and accomplishments; today, however, men's bodies play an integral role in the social construction of masculinity (Soban, 2006). In Western society, being a "real man" means being tough (emotionally and physically), not admitting pain or illness (particularly mental illness or something that would be considered a "woman's problem," such as an eating disor-

Trent A. Petrie, Department of Psychology, University of North Texas; Christy Greenleaf, Department of KHPR, University of North Texas; Justine Reel, Department of Health Promotion and Education, University of Utah; Jennifer Carter, Center for Healthy Living, Worthington, Ohio.

This study was funded by grants from the National Collegiate Athletic Association and the Association for the Advancement of Applied Sport Psychology.

Correspondence concerning this article should be addressed to Trent A. Petrie, Department of Psychology, PO Box 311280, University of North Texas, Denton, TX 76203. E-mail: petriet@unt.edu der), being competitive, and having a desirable and socially ideal physique. This socially idealized physique, which is lean, muscular, strong, and powerful, is to be achieved through work and discipline (physical activity, exercise, and training) and is seen as an outward sign or symbol of masculinity (Drummond, 2002; Gill, Henwood, \& McLean, 2005). It is not surprising, then, that the bodies of male athletes are often idealized.

The sociocultural environment and the social construction of the male gender role have been identified as primary reasons why men are vulnerable for becoming body dissatisfied and developing disordered eating attitudes and behaviors, and why men may be hesitant or even unwilling to admit to engaging in such behaviors and holding such pathological attitudes that traditionally have been viewed as a "woman's problem" (Cafri et al., 2005; Ricciardelli \& McCabe, 2004). Indeed, research has documented the presence, and development over time, of this lean and muscular body ideal 
across many different media outlets, including toy action figures (e.g., G.I. Joe: Baghurst, Hollander, Nardella, \& Haff, 2006; Pope, Olivardia, Gruber, \& Borowiecki, 1999), Playgirl centerfolds (Leit, Pope, \& Gray, 2001; Spitzer, Henderson, \& Zivian, 1999), pictures of male models in men's and women's magazines (Labre, 2005; Pope, Olivardia, Borowiecki, \& Cohane, 2001), and the content of articles and advertisements in magazines (i.e., increasing number on health, fitness, and muscularity: Labre, 2005; Petrie et al., 1996).

Linking these sociocultural changes to disordered eating attitudes and behaviors, Botta (2003) found that reading health and fitness, but not fashion or sport, magazines was associated with increased concern with muscularity (e.g., taking supplements to increase muscle mass), and that adolescent boys who compared their bodies with such media images also reported increased drive for thinness and more bulimic and anorexic behaviors than those who did not regularly make such comparisons. Furthermore, in direct tests of the effects of media exposure on male undergraduates' attitudes and psychological health, researchers found that those who were shown advertisements that contained images of lean and muscular men reported a greater discrepancy between their current and ideal body shapes (Leit et al., 2001) and had higher levels of depression and muscle dissatisfaction (Agliata \& Tantleff-Dunn, 2004) than control groups. These studies suggest that not only has the sociocultural environment changed, communicating to men that they need to achieve a lean and muscular physique, but that men, like women, are negatively affected by these sociocultural messages, specifically becoming more dissatisfied with their bodies, in particular their arms, chests, and abdomens (Ridgeway \& Tylka, 2005), and being more likely to engage in disordered eating behaviors.

Although men in general are at risk because of the presence of these sociocultural pressures, certain subgroups of men, such as athletes, may be even more vulnerable to body dissatisfaction, psychological disturbances, eating disorders, and risky weight loss or weight gain practices. This increased vulnerability is thought to result from factors and pressures unique to the sport environment, such as sport weight limits, team weigh-ins, peer pressures, performance demands, and judging criteria (Petrie \& Rogers,
2001; Petrie \& Sherman, 1999; Swoap \& Murphy, 1995; Thompson \& Sherman, 1999a). For example, in some sports (e.g., wrestling), athletes must make specific weight limits or they cannot compete, whereas in others (e.g., crosscountry), a low body weight is thought to offer a performance advantage. Still, in others (e.g., diving), the aesthetics of the athlete's body strongly influences the outcome of his performance. Thus, in addition to the general pressures that are present for all men, athletes may experience direct and indirect pressures from coaches, teammates, and judges to alter their weight, strength, body size, and appearance in hopes of improving their performances.

Initial research on prevalence suggests that athletes do experience eating disturbances, but that the highest rates are associated with subclinical (as opposed to clinical) levels and with specific pathogenic eating and weight control behaviors. For example, Sundgot-Borgen and Torstveit (2004) reported that $8 \%$ of elite male athletes had some form of an eating disorder (e.g., bulimia nervosa [BN], eating disordernot otherwise specified); Johnson, Powers, and Dick (1999) found that no male collegiate athletes met Diagnostic and Statistical Manual for Mental Disorders (4th ed, text rev.; DSM-IVTR; American Psychiatric Association, 2000) criteria for anorexia nervosa (AN) or BN, but $9.5 \%$ and $38 \%$, respectively, were "at risk" for those disorders. In separate studies of male collegiate athletes, Sanford-Martens et al. (2005) and Carter and Rudd (2005) reported prevalence rates for clinical and symptomatic categories of disorders that ranged from $0.0 \%$ to $1.8 \%$ and $9.3 \%$ to $21.2 \%$, respectively. In a meta-analysis of athlete eating disorder research, Hausenblas and Carron (1999) reported positive effect sizes for male athletes versus nonathletes on three different indices of disordered eating- $\mathrm{BN}, \mathrm{AN}$, and drive for thinness-indicating that athletes had slightly higher rates of disturbance.

Regarding the use of pathogenic eating and weight control behaviors, Johnson et al. (1999) reported that male athletes had lifetime usage rates of $26.6 \%$ (binge eating), $5.9 \%$ (vomiting), $5.1 \%$ (laxatives), $3.7 \%$ (diuretics), and $2.2 \%$ (diet pills); no data were provided on the use of exercise as a weight control technique, even though it has been identified as the primary mechanism that men use to improve 
their body composition and shape (Ridgeway \& Tylka, 2005). Although athletes experience relatively low levels of clinical disorders (e.g., $\mathrm{BN})$, their rates of subclinical disorders and pathogenic eating and weight control behaviors are high. These results suggest that the sport environment indeed may be a risk factor, and that future research will need to examine not only clinical and subclinical concerns but also specific behaviors (e.g., vomiting) that, in and of themselves, may compromise the athletes' health.

Unfortunately, few studies have been completed regarding the prevalence of eating disorders among male athletes, and Petrie and Greenleaf (2007) have pointed out that those have been limited by methodological problems, including the use of single-source samples (e.g., male collegiate athletes drawn from one university, such as found in the Sanford-Martens et al., 2005 , study) and the use of questionnaires to determine prevalence that have no established psychometric properties (e.g., Johnson et al., 1999). In addition, even fewer studies have identified prevalence rates of specific pathogenic weight control behaviors, such as vomiting or taking laxatives. Given the low incidence of diagnosable disorders among male athletes, it is necessary to explore the extent to which they are engaging in specific behaviors that, on their own, may be deleterious to their health and may increase their risk of later developing a fullblown eating disorder.

Given the current state of eating disorder prevalence research among male athletes, the purpose of this study was threefold. First, using a psychometrically reliable and valid measure, we sought to determine the prevalence of both eating disorders and subclinical disordered behaviors among a large and diverse sample of athletes that was drawn from multiple locations. Second, we examined the relation of eating disorder classification (e.g., clinical, asymptomatic) to multiple demographic variables, such as age, sport type, and race/ethnicity. We wanted to test whether the athletes' level of disordered eating varied in relation to these and other demographics and thus determine whether certain athletes may be more at risk than others (e.g., younger vs. older athletes). Third, we wanted to determine the prevalence of specific pathogenic weight control behaviors (e.g., vomiting, exercising) and binge eating (frequency and dura- tion). In considering specific behaviors, we included not only bingeing and traditional forms of purging that are associated with eating disorders, but also exercise frequency because of its relation to the pursuit of the lean and muscular physique among men.

\section{Method}

\section{Participants}

Two hundred three male collegiate athletes from three different National Collegiate Athletic Association (NCAA) Division I institutions located in the Midwest, Southwest, and Mountain regions of the United States participated. Mean age was 20.29 years $(S D=1.64)$. Regarding race/ethnicity, $58.1 \%$ were Caucasian, $1.5 \%$ African American, 30.5\% Hispanic/ Mexican American, and 7.4\% Asian American/ Pacific Islander; $2.5 \%$ indicated "Other." In terms of year in school, $27.6 \%$ were freshmen, $24.6 \%$ sophomores, $28.1 \%$ juniors, and $14.8 \%$ seniors; $4.9 \%$ were in their fifth year.

The men participated in football $(n=102)$, basketball $(n=8)$, cheerleading $(n=5)$, crosscountry $(n=5)$, diving $(n=2)$, fencing $(n=$ $2)$, golf $(n=4)$, ice hockey $(n=4)$, lacrosse $(n=6)$, swimming $(n=13)$, track and field $(n=21)$, volleyball $(n=1)$, alpine skiing $(n=$ $2)$, baseball $(n=25)$, wrestling $(n=2)$, and soccer $(n=1)$. They were involved in their sports an average of 1.93 years $(S D=1.16)$ at the college level and 8.92 years $(S D=5.20)$ during their lifetimes. The majority of the participants were on athletic scholarships (63.3\%) and were starters on their teams $(56.7 \%)$.

The athletes' current body mass index (BMI) was $27.51 \mathrm{~kg} / \mathrm{m}^{2}(S D=5.25$; range $=16.26-46.29)$. In terms of weight categories set by the Centers for Disease Control and Prevention (CDC, n.d.a), $1.5 \%(n=$ 3 ) of the athletes would be classified as underweight (BMI $<18.5), 32.5 \%(n=66)$ as normal weight $(\mathrm{BMI}=18.5-24.9), 42.8 \%$ $(n=87)$ as overweight, and $23.2 \%(n=47)$ as obese. Of those who were in the overweight or obese groups, $67 \%$ were football players. Over half $(60.6 \%)$ of the athletes reported being satisfied with their current weight; of those who were not satisfied, $65.0 \%$ said they were underweight. The majority of the men said that their weight did not fluctuate when they 
were either in season $(82.3 \%)$ or out of season $(78.3 \%)$. In terms of eating disorder histories, 1 reported being diagnosed or treated previously for $\mathrm{AN}$ and 1 for an undefined eating disorder; none indicated $\mathrm{BN}$.

\section{Measures}

Demographics and weight. This questionnaire was developed for the current study to assess age, race/ethnicity, current weight and height, grade level, sport, and years participating in sport. Self-reported current weight and height were used to determine BMI. In addition, the athletes were asked whether they were satisfied with their current weight (and, if not, whether they believed they were overweight or underweight), experienced weight fluctuations when in season and when out of season (changes greater than $10 \%$ body weight), had received an athletic scholarship, were starters on their team, and had a current or past diagnosis or treatment of an eating disorder.

Disordered eating. The 50-item Questionnaire for Eating Disorder Diagnoses (QEDD; Mintz et al., 1997) measures eating disorder symptoms based on DSM-IV-TR criteria; 1 question was changed (see italics) to reflect the reality that athletes exercise as a requirement for their sport (i.e., indicate the amount of time you spent exercising in addition to your normal sport practice in order to lose weight). Based on their responses, participants were classified as eating disordered (i.e., $\mathrm{AN}, \mathrm{BN}$, subthreshold $\mathrm{BN}$, subthreshold $\mathrm{AN}$, nonbingeing $\mathrm{BN}$, and binge-eating disorder), symptomatic (i.e., some symptoms, but not sufficient to warrant a clinical diagnosis), or asymptomatic (i.e., no eating disturbances). Research has supported the QEDD as a valid measure of eating disorder categories for male undergraduates (e.g., Tylka \& Subich, 2002) and male collegiate athletes (e.g., Sanford-Martens et al., 2005).

The 36-item Bulimia Test-Revised (BULIT-R; Thelen, Mintz, \& Vander Wal, 1996) assesses bulimic symptomatology as defined by the DSM-IV-TR. Items are rated on a 5-point scale ranging from 1 (absence of disturbance) to 5 (severe disturbance). Because only 28items are scored, total scores range from 28 to 140; higher scores reflect greater endorsement of bulimic attitudes and behaviors. In addition, for the purposes of this study, 7 of the items were examined because they provided specific information about frequency of use of pathogenic weight control behaviors, such as use of laxatives, diuretics, vomiting, dieting or fasting, excessive exercising, and engagement in binge eating (frequency and duration). Although developed originally with women, recent research has used the BULIT-R in studies with men and thus has provided information on the scale's psychometric properties for this gender. For example, the scale has been found to be internally consistent (Cronbach's alpha) with male undergraduate nonathletes $(\alpha=.90$; Mitchell \& Mazzeo, 2005) and athletes $(\alpha=.87$; Petrie, Greenleaf, Carter, \& Reel, 2007). Cronbach's alpha from the current study was .92. In support of the scale's construct validity, researchers (Mitchell \& Mazzeo, 2005; Petrie et al., 2007) have reported significant correlations between the BULIT-R and symptoms of depression $(r s=.42-.70)$, body satisfaction $(r=-.51)$, and drive for muscularity $(r=.59)$ in samples of undergraduate male athletes and nonathletes. Finally, past research has used the 7 selected items with collegiate athletes to discern the frequency of pathogenic eating and weight loss behaviors (Petrie \& Stoever, 1993).

\section{Procedure}

These data were collected as part of a larger research project on the physical and psychological health of college student athletes that was funded by the NCAA and being conducted at the three schools. After receiving approval from each university's Institutional Review Board for Human Subjects Research, consent was obtained from each athletic department to conduct the study with the athletes. Data collection was coordinated at each site by one of the authors, who arranged with athletic department personnel to have athletes come to on-campus computing centers where they could log onto the confidential Web site to anonymously take the survey. Prior to completing the survey, they read the consent forms and then indicated their agreement by clicking "I agree" on the Web site. No athletic department personnel, including coaches, were present when the athletes completed the online survey. After submitting the survey online, athletes received $\$ 5$ for their participation. Data were collected during the spring semester. 


\section{Data Analysis}

The athletes initially were classified into their eating groups on the basis of their QEDD responses. Once classified, the athletes were compared on several demographic variables, specifically age, race/ethnicity, year in school, and sport team, and on their levels of bulimic symptomatology based on their BULIT-R scores. For the continuous variables (i.e., BULIT-R and age), we made comparisons using an analysis of variance. For the categorical variables, we used chi-square tests. Where appropriate, effect sizes (i.e., partial $\eta^{2}$ and Cohen's $d$ ) are reported. The power for the statistical tests exceeded .90. For the responses to the seven items from the BULIT-R, we calculated simple frequency counts.

\section{Results}

Based on their QEDD responses (Mintz et al., 1997), the athletes were classified as symptomatic $(n=39 ; 19.2 \%)$ and asymptomatic $(n=$ $164 ; 80.8 \%$ ); no athletes were classified as having a clinical eating disorder. To further establish the validity of the QEDD categories for male athletes, we compared the groups on their BULIT-R scores and were found to differ significantly, $F(1,201)=21.01, p<.0001$, partial $\eta^{2}=.10$. As expected, the symptomatic athletes $(M=57.25, S D=16.21$; Cohen's $d=$ .78) reported higher scores in comparison with those who were asymptomatic $(M=45.05$, $S D=14.64)$. Disordered eating group status (symptomatic vs. asymptomatic) was then tested with the demographic variables and found to be unrelated to race/ethnicity (minority vs. nonminority), $\chi^{2}(1, N=203)=1.45, p=$ .23, year in school, $\chi^{2}(4, N=203)=6.72, p=$ .15 , and age, $F(1,201)=0.26, p=.61$, partial $\eta^{2}=.001$ (see Table 1$)$.

To examine the relation between sport team participation and disordered eating status, we classified the teams into one of six groups (Hausenblas \& Carron, 2002): endurance (cross-country, track, swimming; $n=39$; asymptomatic $=34$ and symptomatic $=5$ ); aesthetic (cheerleading, diving; $n=7$; asymptomatic $=5$ and symptomatic $=2$ ); weight dependent (wrestling; $n=2$; asymptomatic $=1$ and symptomatic $=1$ ); ball game (basketball, baseball, soccer, volleyball, hockey, lacrosse; $n=45$; asymptomatic $=36$ and symptomatic $=9$ ); power sports (football, downhill skiing; $n=104$; asymptomatic $=83$ and symptomatic $=21$ ); and technical (fencing, golf; $n=$ 6 ; asymptomatic $=5$ and symptomatic $=1$ ). Because of the small numbers associated with the aesthetic, weight-dependent, and technical groups, it was inappropriate to include them in the analysis. Using the remaining three groups, which had sufficient numbers, there was no significant relation between sport team classification and disordered eating status, $\chi^{2}(2, N=$ $188)=1.30, p=.52$.

Based on the athletes' responses to the seven specific BULIT-R items, 34 (16.7\%) reported binge eating (i.e., eat uncontrollably to the point of stuffing yourself) at least once a week; 35 $(17.2 \%)$ indicated that their binge eating had lasted for 3 months or longer. With respect to the specific pathogenic weight control behaviors, (a) $75(37.0 \%)$ reported exercising at least $2 \mathrm{hr}$ per day to burn calories, (b) 29 $(14.2 \%)$ indicated fasting or going on strict diets at least 2 or more times in the past year, (c) $13(6.5 \%)$ vomited intentionally at least 2-3 times/month, and (d) $9(4.5 \%)$ and 16 $(7.9 \%)$, respectively, reported using diuretics and laxatives at least once a week to control weight (see Table 2).

In summary, none of the athletes were classified with a clinical eating disorder on the basis of their QEDD responses, although almost 20\% reported a sufficient number and level of symptoms to be considered symptomatic. Just over $80 \%$ of the athletes had no significant eating disorder concerns and were classified as aymptomatic. With respect to demographic variables, neither year in school, race/ethnicity, sport type, nor age was related to whether or not the athletes were symptomatic or asymptomatic. In terms of the athletes' body mass, fewer than $2 \%$ were classified as underweight and $66 \%$ as overweight or obese according to CDC guidelines. Despite the high number of athletes who were overweight or obese, just over $60 \%$ expressed being satisfied with their current body weight. Although the total frequency of pathogenic behaviors was low, the athletes indicated that exercise and fasting or dieting were the primary and secondary means for controlling their weight; fewer than $10 \%$ reported using vomiting, laxatives, or diuretics. 
Table 1

Relation of Questionnaire for Eating Disorder Diagnosis Classification to Demographics and Bulimic Symptomatology

\begin{tabular}{|c|c|c|c|c|}
\hline Variable & $\begin{array}{l}\text { Asymptomatic } \\
(n=164)\end{array}$ & $\begin{array}{c}\text { Symptomatic } \\
\quad(n=39)\end{array}$ & $F(1,201)$ & $x^{2}$ \\
\hline Age (years) & & & 0.26 & \\
\hline Mean & 20.26 & 20.41 & & \\
\hline$S D$ & 1.60 & 1.80 & & \\
\hline \multicolumn{5}{|l|}{ BULIT-R } \\
\hline scores & & & $21.01^{*}$ & \\
\hline Mean & 57.25 & 45.05 & & \\
\hline$S D$ & 16.21 & 14.64 & & \\
\hline Sport type & & & & 1.30 \\
\hline Endurance & $87 \%$ & $13 \%$ & & \\
\hline Ball game & $80 \%$ & $20 \%$ & & \\
\hline Power & $78 \%$ & $22 \%$ & & \\
\hline Race/ethnicity & & & & 1.45 \\
\hline Nonminority & $78 \%$ & $22 \%$ & & \\
\hline Minority & $85 \%$ & $15 \%$ & & \\
\hline Year in school & & & & 6.72 \\
\hline Freshman & $80 \%$ & $20 \%$ & & \\
\hline Sophomore & $82 \%$ & $18 \%$ & & \\
\hline Junior & $84 \%$ & $16 \%$ & & \\
\hline Senior & $75 \%$ & $25 \%$ & & \\
\hline
\end{tabular}

Note. $\quad N=203$ for all chi-square tests, and $d f$ s were 2 (Sport type), 1 (Race/ethnicity), and 4 (Year in school). BULIT-R = Bulimia Test-Revised (scores can range from 28 to 140). $* p<.0001$.

\section{Discussion}

Consistent with research that has used the QEDD with single-source samples of male collegiate athletes (Carter \& Rudd, 2005; SanfordMartens et al., 2005), none scored in the clinical eating disorder range, although almost $20 \%$ reported a sufficient number and level of symptoms to be considered symptomatic; just over $80 \%$ had no eating-related concerns and were categorized as asymptomatic. These rates are lower than those reported by Johnson et al. (1999), and generally reflect a low level of eating disorder pathology. Contrary to researchers' findings that sport type or other demographics might be related to eating disorder category (e.g., Sundgot-Borgen \& Torsveit, 2004), neither year in school, race/ethnicity, sport type, nor age was related to whether or not the athletes were symptomatic or asymptomatic. The limitation to these analyses, however, is that the two sport type groupings thought to be most vulnerable to body image concerns and disordered eating behaviors-aesthetic and weight dependent - were excluded because of the small numbers of athletes in each group. As a result, the sport type group analysis, though nonsignificant, was incomplete. Thus, future research will need to continue to examine the relation of sport type groupings (and include all groupings if possible) before firm conclusions can be drawn as to whether or not all groups are equally related to eating disorder classification. Keeping that limitation in mind, these results suggest that the two QEDD groups were similar to one another on the basic demographic variables examined, and there were no disproportionate numbers of certain types of athletes (e.g., sophomores, nonminorities) in either one. Thus, for male collegiate athletes, researchers may be able to aggregate across these demographic variables and certain sport types when conducting analyses based on disordered eating categories, and clinicians will need to recognize that symptomatic athletes may be found among all types of sports, not just those previously thought to be more at risk.

Regarding the athletes' actual body size and their perception of its adequacy, two important findings emerged. First, based on their selfreported weights and heights, two thirds of the 
Table 2

Prevalence of Eating and Pathogenic Weight Control Behaviors $(N=203)$

\begin{tabular}{|c|c|c|}
\hline Behavior & $n$ & $\%$ \\
\hline \multicolumn{3}{|c|}{$\begin{array}{l}\text { Frequency of binge eating (i.e., eat } \\
\text { uncontrollably to the point of stuffing } \\
\text { yourself) }\end{array}$} \\
\hline$>2$ times/week & 12 & 5.9 \\
\hline 2 times/week & 7 & 3.4 \\
\hline Once a week & 15 & 7.4 \\
\hline 2-3 times/month & 17 & 8.4 \\
\hline$<$ Once a month or never & 152 & 74.9 \\
\hline \multicolumn{3}{|l|}{ Duration of binge eating } \\
\hline 3 or more years & 16 & 7.9 \\
\hline 1 to 3 years & 9 & 4.4 \\
\hline 3 months to one year & 10 & 4.9 \\
\hline Less than 3 months & 8 & 3.9 \\
\hline Don't binge eat & 160 & 78.8 \\
\hline \multicolumn{3}{|l|}{ Exercise in order to burn calories } \\
\hline$>2$ hours/day & 33 & 16.3 \\
\hline 2 hours/day & 42 & 20.7 \\
\hline 1-2 hours/day & 20 & 9.9 \\
\hline$<1$ hour/day & 14 & 6.9 \\
\hline Don't exercise to burn calories & 94 & 46.3 \\
\hline \multicolumn{3}{|c|}{$\begin{array}{l}\text { Tried to lose weight by fasting or going on } \\
\text { strict diets }\end{array}$} \\
\hline$>5$ times in past year & 13 & 6.4 \\
\hline 4-5 times in past year & 7 & 3.4 \\
\hline $2-3$ times in past year & 9 & 4.4 \\
\hline Once in past year & 18 & 8.9 \\
\hline Not in past year & 156 & 76.8 \\
\hline \multicolumn{3}{|l|}{ Intentionally vomit after eating } \\
\hline$\geq$ Twice a week & 4 & 2.0 \\
\hline Once a week & 6 & 3.0 \\
\hline 2-3 times/month & 3 & 1.5 \\
\hline Once a month & 0 & 0.0 \\
\hline$<$ Once a month or never & 190 & 93.6 \\
\hline \multicolumn{3}{|c|}{ Use diuretics to help control weight } \\
\hline$\geq 3$ times/week & 3 & 1.5 \\
\hline $1-2$ times/week & 6 & 3.0 \\
\hline 2-3 times/month & 5 & 2.5 \\
\hline Once a month & 9 & 4.4 \\
\hline$<$ Once a month or never & 180 & 88.7 \\
\hline \multicolumn{3}{|c|}{$\begin{array}{l}\text { Use laxatives/suppositories to help control } \\
\text { weight }\end{array}$} \\
\hline$\geq$ Once a day & 8 & 3.9 \\
\hline 3-6 times/week & 3 & 1.5 \\
\hline 1-2 times/week & 5 & 2.5 \\
\hline 2-3 times/month & 0 & 0.0 \\
\hline$<$ Once a month or never & 187 & 92.1 \\
\hline
\end{tabular}

sample was classified as overweight or obese, a strikingly large number given population estimates that are much lower, around 32\% (CDC, n.d.b). Because self-reported weights and heights have been found to be valid measures, the reason for the higher prevalence rates of overweight or obesity in this sample are likely due to the fact that the participants were athletes, and that $67 \%$ of those who were overweight or obese played football, and not inaccuracy in how their BMIs were measured or calculated. Athletes generally have a greater ratio of lean muscle mass to body fat in comparison with nonathletes (CDC, n.d.a), and thus their large BMIs are more representative of muscularity than body fatness than would be expected among those who do not participate in sports at an advanced level but have similar BMIs.

A second major finding relating to actual body size was that fewer than $2 \%$ of the athletes were underweight on the basis of their BMIs, yet over one quarter of them were dissatisfied with their weight and stated that this dissatisfaction was due to their feeling underweight (and wanting to gain weight). This finding makes sense given the performance demands associated with sport and the advantages that come from being stronger and more muscular (and thus heavier). This finding also is consistent with past research that has shown men's dissatisfaction with their weight and body size to be due primarily to being underweight and to possessing inadequate musculature (e.g., McCabe \& Ricciardelli, 2004; Raudenbush \& Meyer, 2003). For example, Raudenbush and Meyer (2003) reported that the collegiate male athletes they examined believed their actual physique was smaller, lighter, and less muscular than their ideal sport physique as well as the physique they believed was attractive to the opposite sex. Thus, male athletes appear to experience pressure to achieve a lean, muscular physique, not only to improve their sport performances, but also to be considered attractive by women. These pressures or drive to achieve a muscular physique are associated with a host of negative psychological outcomes, including lower self-esteem, disordered eating behaviors, the tendency to compare one's appearance to others, and internalization of the sociocultural ideal of attractiveness (Tylka, Bergeron, \& Schwartz, 2005).

Although male athletes generally consume large quantities of food, a necessary reality so they can meet their energy expenditure needs, the majority (74.9\%) indicated that they did not binge eat. This finding suggests that male athletes likely consume large quantities of food, 
but generally do not define this consumption as a binge, most likely because they do not feel out of control when eating (the key component for a binge). Of those who did define their food intake as a binge, their frequency was generally low, with only $9.3 \%$ binge eating often enough to meet clinical diagnostic criteria (at least twice per week); it is interesting, however, that the majority of the sample who did binge eat had done so for more than the 3 months required for clinical diagnosis. When similar frequencies of binge eating were considered (i.e., weekly or more), more athletes in the current study binge ate than has been reported in past research with male collegiate athletes (Carter \& Rudd, 2005; Johnson et al., 1999).

Because the data from this study were drawn from multiple sites, it is unlikely that the higher prevalence is simply due to unique characteristics of the sample. In fact, it may be that the increase reflects true changes in male athletes' eating behaviors. It would not be surprising for athletes, particularly those who feel underweight (which was one quarter of the current sample), to eat more food in an attempt to gain weight. Although many male athletes could increase their food intake without experiencing any problems, others, particularly those who have internalized the general and sport-specific sociocultural pressures regarding weight, body type, and sport performance, may have difficulty regulating their food intake, knowing when they truly are hungry, knowing when they are full, and not eating as means of coping with their emotional state (Tylka, 2006). With the changes that have occurred in the sociocultural environment during the past 2 decades, men now appear to be experiencing some of the same eating-related pressures that historically have been present for female athletes and to be responding behaviorally in similar ways (Cafri et al., 2005).

Regarding the pathogenic weight control behaviors, whose overall frequencies were relatively low and did not indicate high levels of pathology, the athletes used exercise as their primary and fasting or dieting as their secondary means for controlling their weight, which is consistent with research with female collegiate athletes (Petrie \& Stoever, 1993) and male collegiate nonathletes (Ridgeway \& Tylka, 2005). The use of these two approaches, in particular exercise, makes sense because they are readily available to athletes, and it is easy to hide the intent of the behavior. That is, athletes can work out for more hours than required by their coaches and actually be viewed as "good athletes" for their approach to physical training (Thompson \& Sherman, 1999b). What is not clear, however, is whether male athletes enter their collegiate sport teams with unhealthy exercise regimens already in use or such regimens develop as a result of the increased pressures and demands they experience at this higher level of sport. To address this question, longitudinal research is needed that tracks male athletes across time, such as from the beginning of high school through their first two years of college. Even though the causal pathway is not determined, professionals who work with male athletes should consider that extensive working out may be a signal of problematic eating attitudes and behaviors as much as it is a sign of dedication to training and take steps to talk with these athletes about their motivations for engaging in their exercise regimens.

Again, although the overall frequency was low, the male athletes in our sample used traditional forms of purging (e.g., vomiting) at rates higher than have been found previously with other male collegiate athletes (Carter \& Rudd, 2005; Johnson et al., 1999) and nonathletes (O'Dea \& Abraham, 2002) and consistent with what has been reported among female collegiate athletes (Petrie \& Stoever, 1993). These relatively higher rates of pathogenic weight control behaviors are of concern because vomiting and laxative abuse are associated with severe medical complications, such as dehydration, esophageal tears, and cardiac arrhythmia (Rome \& Ammerman, 2003), and may be precursors to the development of actual eating disorders. In addition, because we inquired only about these traditional forms of purging, we cannot rule out the possibility that the athletes were engaging in other problematic behaviors, such as ingesting muscle mass-weight gain supplements (e.g., Creatine), to control their weight and reshape their bodies (Raudenbush \& Meyer, 2003). In future prevalence research with male athletes, it will be important (if allowed by coaches and athletic departments) to include a larger list of potential weight control behaviors, such as taking supplements or anabolic steroids, and to ask more detailed questions about the types of ex- 
ercise that male athletes are using to shape their bodies. For now, however, health professionals who work with male collegiate athletes should be aware that these athletes are using traditional purging behaviors at relatively high rates and should monitor them for signs of physical complications that may be life threatening.

Despite the improvements made for this study-use of a psychometrically sound measure of disordered eating, sample drawn from three institutions-limitations exist that warrant discussion. The primary limitation concerned the sole use of a self-report questionnaire to establish the prevalence rates of the disordered eating categories as well as the eating and pathogenic weight behaviors. Because eating disorder symptoms generally are underreported (Beglin \& Fairburn, 1992), and are likely to be more so among men who may perceive eating disorders as a woman's problem and thus be less willing to admit their own distress because of the stigma they may be feeling (Soban, 2006), it is likely that the prevalence rates found in this study fall short of the real levels of disturbance. Although difficult to implement because of issues of time and access to athletes, to address this limitation, future research may want to include follow-up clinical interviews to verify diagnostic status, as was done by Sundgot-Borgen and Torstveit (2004). Specifically, valid measures, like the QEDD, could be used to screen large samples of athletes. Those who score as either eating disordered or symptomatic could be interviewed by a psychologist using a structured interview procedure to verify diagnosis. In addition, during these interviews, researchers could explore in more depth how men experience their disordered eating attitudes in terms of their bodies and their psychological and emotional functioning. Such an approach would provide additional validity data regarding the use of the QEDD with athletes; establish even more accurate prevalence rates; identify those athletes who are suffering from an eating disorder or who are at risk and could benefit from treatment; and provide a richer, more complete psychological picture of male athletes who have eating disorders.

A second limitation concerned the questionnaires used in this study. Although reliable and valid, the measures did not address the specific forms of exercise in which the athletes engaged (just the amount of time they spent exercising to control their weight), their motivation for exercising (e.g., weight loss vs. increase muscularity), or their use of other health risk behaviors, such as the ingestion of nutritional supplements or anabolic steroids. Given that some male athletes want to gain weight and others want to lose weight, it will be important in future studies to explore directly their reasons for exercising to better understand their underlying motivations. In addition, because men may be more likely to use pathogenic weight gain behaviors than develop full-blown eating disorders (Cafri et al., 2005), researchers should examine specifically men's (athlete or nonathlete) use of Creatine, ephedrine, anabolic steroids, and dieting to gain weight or muscularity.

Despite these limitations, this study's findings have implications for mental health professionals who work with male collegiate athletes. First, substantial numbers of male athletes can be classified as symptomatic using traditional measures of eating disorders. That is, they experience many of the established symptoms of eating disorders, only at a subclinical level. These problems exist across sport type, racial/ ethnic group, year in school, and age of the athlete, and may be a precursor for a full-blown eating disorder if left untreated. Thus, mental health professionals who work with this population will need to look beyond any biases they hold that eating disorders are a woman's issue only and recognize that they exist for men as well (Soban, 2006).

Second, although male athletes experience clinical levels of eating pathology at lower rates than their female counterparts, they appear to have similar levels of disturbances when specific pathogenic weight control behaviors are considered. It may be that, because of the unique pressures that men feel to be large, lean, and more muscular (as opposed to the drive to be thinner that women experience), they are less likely to develop an eating disorder as currently conceptualized. Instead, they may experience a cluster of problems, such as depression, anxiety, body dissatisfaction (not believing they are muscular enough), poor self-concept, substance abuse (e.g., alcohol), and excessive exercising (with a focus on weight gain behaviors, such as weight lifting), that represent serious health risks but 
do not fit into existing diagnostic categories. Thus, when men present with any one of these or related problems, mental health practitioners should be willing to inquire further into their clients' eating and weight control behaviors to determine whether there are more severe or extensive problems (Davey \& Bishop, 2006).

Finally, and related to the second point, because of how masculinity currently is defined, men may be more willing to report or admit to certain behaviors (e.g., exercising excessively, drinking alcohol), attitudes (e.g., not believing their bodies are muscular enough), or feelings (e.g., anger) than they would having an actual eating disorder. Even though over the past 2 decades men's pursuit of eating disorder treatment has increased (Braun et al., 1999), most men do not seek assistance because of a variety of real and perceived barriers, such as oversubscribing to masculine gender roles and the stigma of having a "woman's illness." Thus, when counseling men, mental health practitioners may want to focus on these more accessible problem areas first, and use them as the entry point to more broadly discuss their clients' eating behaviors, conception of themselves as a man, and the possibility that they are suffering from an eating disorder (Soban, 2006).

Using a diverse sample, drawn from three universities located across three regions of the United States, and a psychometrically valid questionnaire, we identified prevalence rates for eating disorders and specific pathogenic weight control behaviors among male collegiate athletes. Although their overall level of clinical eating pathology was very low, a substantial number experience subclinical concern that may be precursors to the later development of an actually diagnosable disorder. In fact, a subset of the athletes engaged in eating and weight control behaviors that, in and of themselves, represent severe health risks. Thus, male collegiate athletes need special attention from researchers and practitioners to address the disordered eating attitudes and behaviors that do exist among this group of at-risk men. In particular, professionals need to reach out to this group of men, both in terms of research and intervention, because of their hesitancy to report the eating and body-related problems they are experiencing.

\section{References}

Agliata, D., \& Tantleff-Dunn, S. (2004). The impact of media exposure on males' body image. Journal of Social and Clinical Psychology, 23, 7-22.

American Psychiatric Association. (2000). Diagnostic and statistical manual for mental disorders $\left(4^{\text {th }}\right.$ ed., text rev.). Washington, DC: Author.

Baghurst, T., Hollander, D. B., Nardella, B., \& Haff, G. G. (2006). Change in sociocultural ideal male physique: An examination of past and present action figures. Body Image, 3, 87-91.

Beglin, S., \& Fairburn, C. (1992). Women who choose not to participate in surveys on eating disorders. International Journal of Eating Disorders, 12, 113-116.

Botta, R. A. (2003). For your health? The relationship between magazine reading and adolescents' body image and eating disturbances. Sex Roles, 48, 389-399.

Cafri, G., Thompson, J. K., Ricciardelli, L., McCabe, M., Smolak, L., \& Yesalis, C. (2005). Pursuit of the muscular ideal: Physical and psychological consequences and putative risk factors. Clinical Psychology Review, 25, 215-239.

Carter, J. E., \& Rudd, N. A. (2005). Disordered eating assessment for college student athletes. Women in Sport and Physical Activity Journal, 14, 62-71.

Centers for Disease Control and Prevention. (n.d.a). How is BMI calculated and interpreted? Retrieved March 20, 2008, from http://www.cdc.gov/nccdphp/dnpa/bmi/ adult_BMI/about_adult_BMI.htm\#Interpreted

Centers for Disease Control and Prevention. (n.d.b). Overweight and obsesity. Retrieved March 26, 2008, from http://www.cdc.gov/nccdphp/dnpa/ obesity/index.htm

Davey, C., \& Bishop, J. (2006). Muscle dysmorphia among college men: An emerging gender-related counseling concern. Journal of College Counseling, 9, 171-180.

Drummond, M. (2002). Men, body image, and eating disorders. International Journal of Men's Health, 1, 79-93.

Gill, R., Henwood, K., \& McLean, C. (2005). Body projects and the regulation of normative masculinity. Body \& Society, 11, 37-62.

Hausenblas, H. A., \& Carron, A. V. (1999). Eating disorder indices and athletes: An integration. Journal of Sport \& Exercise Psychology, 21, 230-258.

Hausenblas, H. A., \& Carron, A. V. (2002). Assessing eating disorder symptoms in sport groups: A critique with recommendations for future research. International Sports Journal, 6, 65-74.

Johnson, C., Powers, P. S., \& Dick, R. (1999). Athletes and eating disorders: The National Collegiate Athletic Association study. International Journal of Eating Disorders, 26, 179-188. 
Labre, M. P. (2005). Burn fat, build muscle: A content analysis of Men's Health and Men's Fitness. International Journal of Men's Health, 4, 187-200.

Leit, R. A., Pope, H. G., \& Gray, J. J. (2001). Cultural expectations of muscularity in men: The evolution of Playgirl centerfolds. International Journal of Eating Disorders, 29, 90-93.

McCabe, M. P., \& Ricciardelli, L. A. (2004). Body image dissatisfaction among males across the lifespan: A review of past literature. Journal of Psychosomatic Research, 56, 675-685.

Mintz, L. B., O’Halloran, M. S., Mulholland, A. M., \& Schneider, P. A. (1997). Questionnaire for eating disorder diagnoses: Reliability and validity of operationalizing $D S M-I V$ criteria into a self-report format. Journal of Counseling Psychology, 44, 63-79.

Mitchell, K. S., \& Mazzeo, S. E. (2005). Mediators of the association between abuse and disordred eating in undergraduate men. Eating Behaviors, 6, 318-327.

Petrie, T., Austin, L., Crowley, B., Helmcamp, A., Johnson, C., Lester, R., et al. (1996). Sociocultural expectations of attractiveness for males. Sex Roles, 35, 581-602.

Petrie, T. A., \& Greenleaf, C. (2007). Eating disorders in sport: From theory to research to intervention. In G. Tenenbaum \& R. Eklund (Eds.), Handbook of sport psychology (3rd ed., pp. 352-378). Hoboken, NJ: Wiley.

Petrie, T. A., Greenleaf, C., Carter, J. E., \& Reel, J. J. (2007). Psychosocial correlates of disordered eating among male collegiate athletes. Journal of Clinical Sport Psychology, 1, 340-357.

Petrie, T. A., \& Rogers, R. (2001). Extending the discussion of eating disorders to include men and athletes. The Counseling Psychologist, 29, 743753.

Petrie, T., \& Sherman, R. (1999). Recognizing and assisting athletes with eating disorders. In R. Ray \& D. Wiese-Bjornstal (Eds.), Counseling in sports medicine (pp. 205-226). Champaign, IL: Human Kinetics.

Petrie, T. A., \& Stoever, S. (1993). The incidence of bulimia nervosa and pathogenic weight control behaviors in female collegiate gymnasts. Research Quarterly for Exercise and Sport, 64, 238-241.

Pope, H. G., Jr., Olivardia, R., Borowiecki, J. J., III, \& Cohane, G. H. (2001). The growing commercial value of the male body: A longitudinal survey of advertising in women's magazines. Psychotherapy and Psychosomatics, 70, 189-192.

Pope, H. G., Olivardia, R., Gruber, A., \& Borowiecki, J. (1999). Evolving ideals of male body image as seen through action toys. International Journal of Eating Disorders, 26, 65-72.

Raudenbush, B., \& Meyer, B. (2003). Muscular dissatisfaction and supplement use among male inter- collegiate athletes. Journal of Sport \& Exercise Psychology, 25, 161-170.

Ricciardelli, L. A., \& McCabe, M. P. (2004). A biopsychosocial model of disordered eating and the pursuit of muscularity in adolescent boys. Psychological Bulletin, 130, 179-205.

Ridgeway, R. T., \& Tylka, T. L. (2005). College men's perceptions of ideal body composition and shape. Psychology of Men \& Masculinity, 6, 209-220.

Rome, E., \& Ammerman, S. (2003). Medical complications in eating disorders: An update. Journal of Adolescent Health, 33, 418-426.

Sanford-Martens, T. C., Davidson, M. M., Yakushko, O. F., Martens, M. P., Hinton, P., \& Beck, N. (2005). Clinical and subclinical eating disorders: An examination of collegiate athletes. Journal of Applied Sport Psychology, 17, 79-86.

Soban, C. (2006). What about the boys? Addressing issues of masculinity within male anorexia nervosa in a feminist therapeutic environment. International Journal of Men's Health, 5, 251-267.

Spitzer, B. L., Henderson, K. A., \& Zivian, M. T. (1999). Gender differences in population versus media body sizes: A comparison over four decades. Sex Roles, 40, 545-565.

Sundgot-Borgen, J., \& Torstveit, M. K. (2004). Prevalence of eating disorders in elite athletes is higher than in the general population. Clinical Journal of Sports Medicine, 14, 25-32.

Swoap, R., \& Murphy, S. (1995). Eating disorders and weight management in athletes. In S. Murphy (Ed.), Sport psychology interventions (pp. 307329). Champaign, IL: Human Kinetics.

Thelen, M. H., Mintz, L. B., \& Vander Wal, J. S. (1996). The Bulimia Test-Revised: Validation with DSM-IV criteria for bulimia nervosa. Psychological Assessment, 2, 219-221.

Thompson, R., \& Sherman, R. (1999a). Athletes, athletic performance, and eating disorders: Healthier alternatives. Journal of Social Issues, 55, 317-337.

Thompson, R., \& Sherman, R. (1999b). "Good athlete" traits and characteristics of anorexia nervosa: Are they similar? Eating Disorders, 7, 181-190.

Tylka, T. L. (2006). Development and psychometric evaluation of a measure of intuitive eating. Journal of Counseling Psychology, 53, 226-240.

Tylka, T. L., Bergeron, D., \& Schwartz, J. P. (2005). Development and psychometric evaluation of the Male Body Attitudes Scale (MBAS). Body Image, 2, 161-175.

Tylka, T. L., \& Subich, L. M. (2002). A preliminary investigation of the eating disorder continuum with men. Journal of Counseling Psychology, 49, 273 279.

Received November 12, 2007

Revision received May 1, 2008 Accepted June 10, 2008 